\title{
PENGARUH VARIASI TEMPERATUR TEMPERING TERHADAP SIFAT MEKANIK DAN SIFAT FISIK BAJA AISI 1045 SEBAGAI BAHAN PISAU MESIN PENCACAH PLASTIK
}

\author{
Khalid $^{1}$, Kardiman ${ }^{2}$, Viktor Naubnome ${ }^{3}$ \\ ${ }^{1,2,3}$ Program Studi Teknik Mesin, Fakultas Teknik Universitas Singaperbangsa Karawang, \\ ${ }^{1}$ Khalidismail224@gmail.com
}

\begin{abstract}
ABSTRAK
Pisau merupakan suatu komponen pemesinan yang digunakan untuk memotong benda menjadi potongan dan bagian, begitu juga dengan pisau mesin pencacah plastik yang diharapkan bisa memotong plastik menjadi ukuran yang lebih kecil, dengan hasil potongan yang lebih kecil dapat memudahkan pada proses selanjutnya dan diolah menjadi produk jadi lainnya.

Untuk menghasilkan potongan yang lebih kecil dilakukanlah peningkatan pisau dari sifat fisik dan mekanik nya melalui proses perlakuan panas, perlakuan panas ini digunakan untuk meningkatkan kekerasan pisau pemotong pada mesin pencacah plastik agar didapat kinerja pisau pemotong yang maksimal.

Metode perlakuan panas yang digunakan yaitu proses tempering dengan variasi temperatur $300^{\circ} \mathrm{C}, 400^{\circ} \mathrm{C}$, dan $500^{\circ} \mathrm{C}$. Material yang digunakan pada pisau pemotong ini adalah baja AISI 1045. Dari data hasil pengujian kekerasan dengan metode vickers yang ditampilkan pada tabel dan grafik terlihat peningkatan kekerasan baja yang berbeda, selanjutnya dianalisa dan didapat nilai rata - rata kekerasan raw material sebesar $211 \mathrm{HV}$, kemudian baja yang ditempering dengan temperatur $300^{\circ} \mathrm{C}$ memiliki nilai kekerasan $257,73 \mathrm{HV}$, selanjutnya untuk tempering dengan temperatur $400^{\circ} \mathrm{C}$ memiliki nilai kekerasan $269,3 \mathrm{HV}$, dan untuk hasil tempering dengan temperatur $500^{\circ} \mathrm{C}$ memliki nilai kekerasan 250 HV.
\end{abstract}

Kata kunci: Pisau pemotong, Tempering, dan Kekerasan Vickers.

\begin{abstract}
The knife is a machining component that is used to cut objects into pieces and parts, as well as a plastic chopping machine knife which is expected to be able to cut plastic into smaller sizes, with smaller pieces making it easier for the next process and processed into other finished products. .

To produce smaller pieces, an increase in the physical and mechanical properties of the blade is carried out through a heat treatment process, this heat treatment is used to increase the hardness of the cutting blade on the plastic chopping machine in order to obtain maximum cutting blade performance.

The heat treatment method used is the tempering process with temperature variations of $300^{\circ} \mathrm{C}, 400^{\circ} \mathrm{C}$, and $500^{\circ} \mathrm{C}$. The material used in this cutting knife is AISI 1045 steel.From the data from the hardness test results using the Vickers method shown in the table and graph, it can be seen that the hardness of different steels has increased, then analyzed and the average value of raw material hardness is $211 \mathrm{HV}$, then steel tempered with a temperature of $300^{\circ} \mathrm{C}$ has a hardness value of 257, $73 \mathrm{HV}$, then for tempering with a temperature of $400{ }^{\circ} \mathrm{C}$ it has a hardness value of $269,3 \mathrm{HV}$, and for tempering results with a temperatureof $500^{\circ} \mathrm{C}$ it has a hardness valueof $250 \mathrm{HV}$.
\end{abstract}

Keywords: Cutting Blade,Tempering and Vickers Hardness. 


\section{PENDAHULUAN}

Proses Tempering merupakan suatu proses memanaskan kembali baja yang telah dipanaskan (heating) atau dikeraskan di bawah suhu kritis (tempering) yang kemudian dilanjutkan dengan proses pendinginan (quenching). Tujuan dari proses ini adalah meningkatkan nilai kekerasan dan keuletan pada material baja. Baja yang digunakkan yaitu baja AISI 1045 dengan kandungan karbon sampai $0,50 \%$, baja ini sangat banyak digunakan untuk bahan komponen - komponen mesin, baik komponen transmisi, atau komponen kontruksi yang lain[1].

Karakteristik material AISI 1045 sebagai bahan pisau pemotong ini memerlukan sifat yang diantaranya keras, tangguh dan tahan aus. Hal ini dapat dilihat dari sifat fisik dan mekanik material tersebut, untuk sifat fisik dari pisau tanpa perlakuan panas diketahui hanya terbentuk fasa pearlite dan ferrite yang artinya material yang dihasilkan masih lunak dan tingkat kekerasannya belum cukup tinggi. Tingkat kekerasan tinggi dapat dihasilkan apabila material sudah membentuk fasa martensite yang dominan. Sementara sifat mekanik dari pisau tanpa perlakuan panas dihasilkan melalui uji kekerasan untuk mengetahui nilai kekerasan material[2].

Proses Heat Treatment ini bertujuan untuk meningkatkan dan memperbaiki sifat fisik dan mekanik material yang nantinya akan dijadikan sebagai bahan baku pisau pemotong, dengan dilakukannya perlakuan panas material dapat mengahasilkan tingkat kekerasan dan ketahanan aus yang tinggi. Material pisau pemotong diharapkan mencapai tingkat kekerasan yang tinggi agar pisau tersebut dapat memotong plastik secara berulang kali dan mendapatkan hasil potongan yang lebih baik[3].

Proses perlakuan panas ini menggunakan metode tempering dengan memperhatikan pada temperatur pemanasan dibuat variasi untuk didapat temperatur yang sesuai pada material yang akan digunakan pada bahan pisau pemotong. Penelitian Agus Pramono (2011) menyatakan Proses perlakuan panas dapat dipengaruhi oleh beberapa parameter tertentu yang diantaranya, temperatur pemanasan, waktu pemanasan dan waktu penahanan[4].
Pada penelitian ini menggunakan media quenching oli SAE karena meiliki laju pendinginan yang lebih lambat, dengan laju pendinginan lambat dapat mengurangi hasil distorsi yang dihasilkan. Yunaidi (2015) menyatakan penggunaan media pendingin oli dapat memberikan hasil quenching dengan distorsi dan retak yang lebih kecil[5]

Berdasarkan uraian dari penelitian - penelitian di atas, maka penulis melakukan penelitian mengenai proses Heat treatment menggunakan metode Tempering pada baja AISI 1045 dengan variasi temperatur tempering. Penelitian ini bertujuan untuk mendapatkan nilai kekerasan dan struktur mikro pada baja AISI 1045 yang melalui proses perlakuan panas menggunakan metode tempering.

\section{METODE}

Penelitian ini dilakukan di Balai Besar Bahan dan Barang Teknik (B4T), dalam penelitian ini meliputi uji sifat fisik dan mekanik. Pengujian sifat fisik dilakukan melalui pengamatan struktur mikro untuk didapat hasil fasa apa saja yang terbentuk, sedangkan pengujian sifat mekanik dilakukan menggunakan metode vickers untuk mengetahui nilai kekerasan dari material benda uji. Bahan yang digunakan dalam penelitian ini adalah baja AISI 1045 dengan kandungan karbon sampai 0,50\%, mangan sampai $0,80 \%$, dan Posfor maksimum $0,035 \%[6]$.

1. Pembuatan spesimen benda uji menggunakan mesin gergaji dan mesin bubut untuk memotong dan membentuk spesimen uji sesuai standar yang diperlukan. Dimensi sampel uji $\varnothing=20 \mathrm{~mm}$ dan tebal $=10 \mathrm{~mm}$. Ukuran tebal disamakan dengan komponen pisau mesin pencacah plastik. 

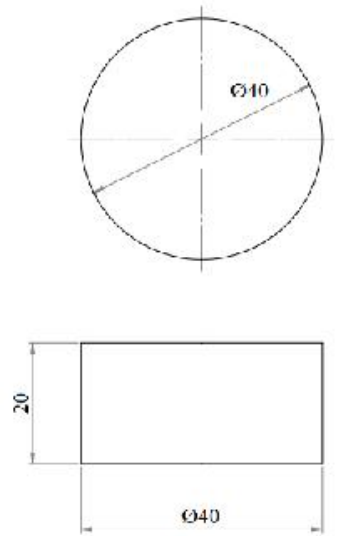

Gambar 1. Dimensi Spesimen Uji

2. Proses pemanasan awal (heating) pada temperatur austenite $850^{\circ} \mathrm{C}$ dengan waktu penahanan 60 menit.[1] Kemudian diikuti proses quenching dengan media oli, lalu dilanjutkan dengan proses tempering dengan variasi temperatur $300^{\circ} \mathrm{C}, 400^{\circ} \mathrm{C}$, dan $500^{\circ} \mathrm{C}$ dengan waktu penahanan 30 menit. Setelah proses perlakuan panas selesai, setiap spesimen didinginkan dengan udara sampai temperatur kamar.

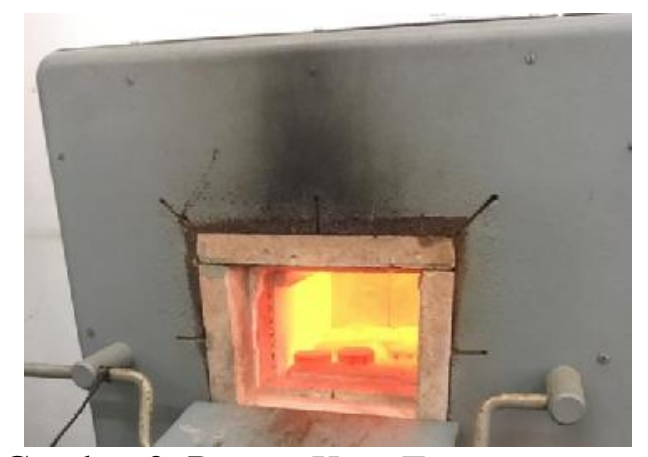

Gambar 2. Proses Heat Treatment

3. Pengujian Sifat mekanik melalui uji kekerasan untuk menyatakan ukuran ketahanan suatu logam serta memperoleh nilai kekarasannya. Pengujian Kekerasan ini menggunakan Metode Vickers dengan Standar ASTM E 92-82 (Reapproved 2003) (Standard Test Method for Vickers Hardness of Metallic Material).

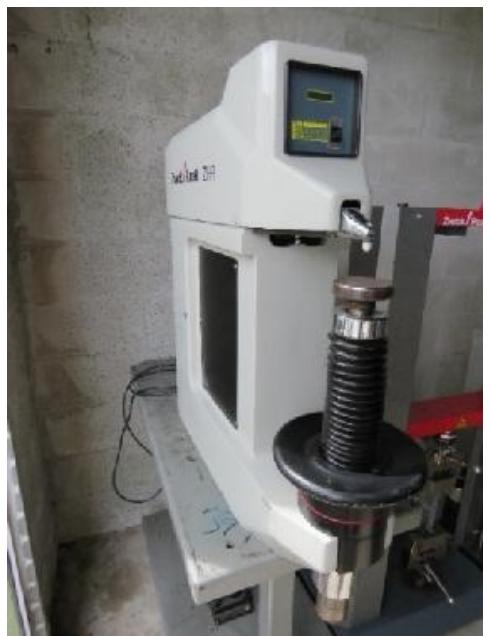

Gambar 3. Vickers Hardness Tester

4. Pengujian Sifat fisik melalui pengamatan Struktur Mikro yang bertujuan untuk mengetahui struktur fasa apa saja yang diketahui dan dapat dihasilkan tingkat kekerasan material. Pengujian Struktur mikro ini menggunakan standar ASTM E-407, dan alat yang digunakkan yaitu Microscope BX53M dan ZWICK NS : 61029.

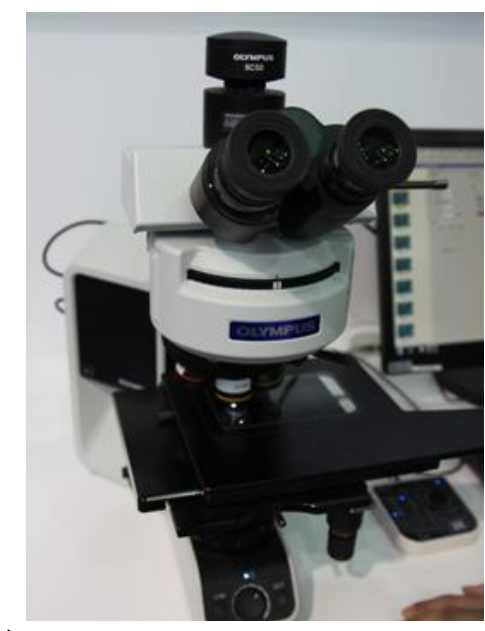

Gambar 4. Microscope BX53M dan ZWICK NS : 61029 


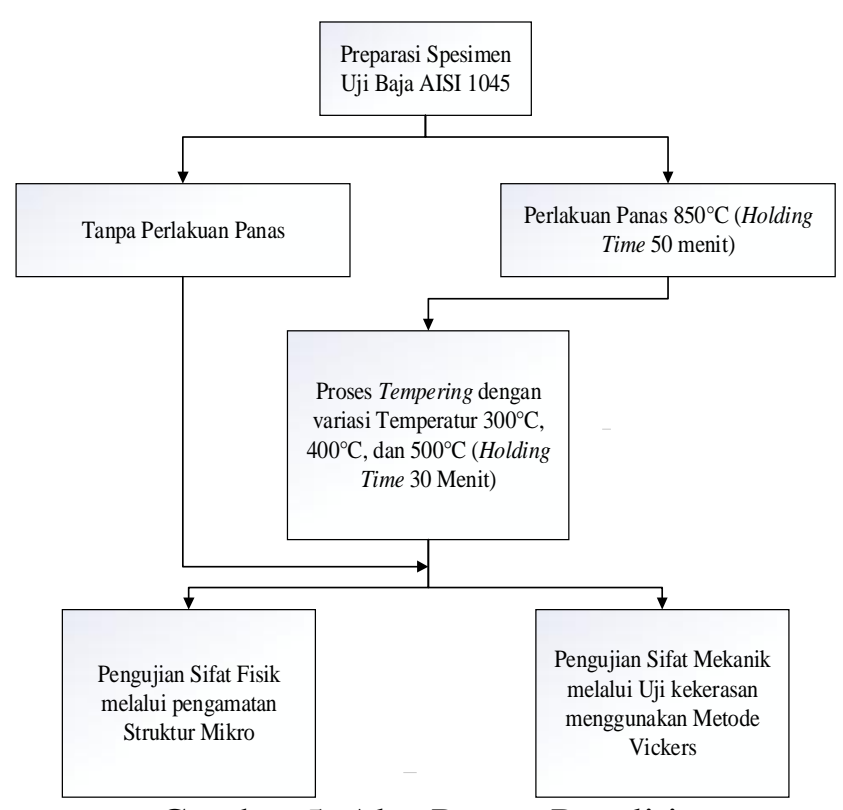

Gambar 5. Alur Proses Peneliti

\section{HASIL DAN PEMBAHASAN}

Dari Pengujian diperoleh perbedaan nilai kekerasan antara sebelum dan sesudah dilakuakan perlakuan panas dan pendinginan terhadap baja AISI 1045.

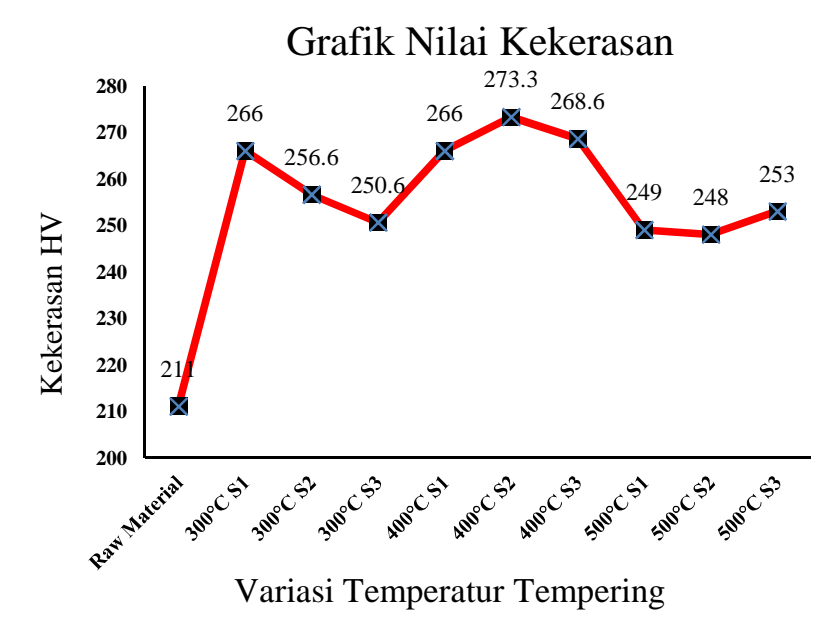

Gambar 6. Grafik Nilai Kekerasan

22

Berdasarkan Gambar 7. Grafik Nilai Kekerasan menunjukan nilai kekerasan yang berbeda - beda dari tiap variasi temperatur tempering. Pada temperatur $300^{\circ} \mathrm{C}$ didapat nilai rata - rata sebesar 257.73 HV, temperatur $400^{\circ} \mathrm{C}$ sebesar $269,3 \mathrm{HV}$, dan temperatur $500^{\circ} \mathrm{C}$ sebesar $250 \mathrm{HV}$. Sedangkan untuk spesimen uji tanpa perlakuan panas (raw material) memiliki nilai kekerasan sebesar $211 \mathrm{HV}$.

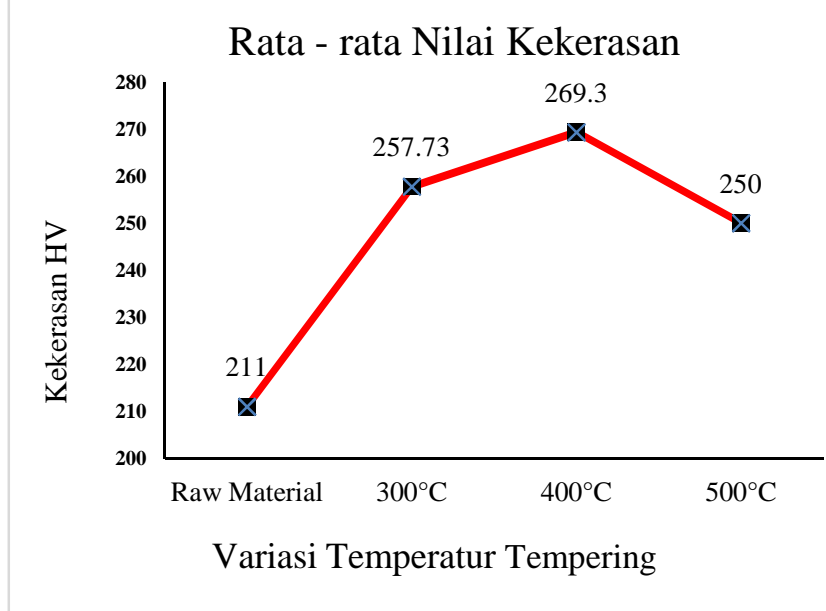

Gambar 7. Rata - rata Nilai Kekerasan

Pada Gambar 8. Rata - rata nilai kekerasan diketahui nilai kekerasan tertinggi terdapat pada variasi temperatur $400^{\circ} \mathrm{C}$ dengan nilai $269,3 \mathrm{HV}$, sedangkan nilai kekerasan terendah pada variasi temperatur $500^{\circ} \mathrm{C}$ dengan nilai $250 \mathrm{HV}$. Maka dalam hal ini proses perlakuan panas yang menggunakan metode tempering berpengaruh terhadap nilai kekerasan spesimen uji dan juga menambah sifat - sifatnya yang diantaranya kekerasan, keuletan serta tegangan tariknya.

Berbeda dengan hasil penelitian yang dilakukan (Awan Jaya Miharja 2016) menjelaskan bahwa spesimen uji yang dilakukan proses temper $300^{\circ} \mathrm{C}$ memiliki kekerasan paling tinggi yaitu sebesar 42,67 HRC, diikuti dengan temper $450^{\circ} \mathrm{C}$ sebesar 41,83 HRC, dan temper $600^{\circ} \mathrm{C}$ sebesar 35,17 HRC. Hasil berikut dapat disimpulkan bahwa semakin tinggi temperatur tempering menyebabkan rendahnya nilai kekerasan[7].

Selanjutnya yaitu Pengujian Sifat fisik melalui pengamatan struktur Mikro yang bertujuan untuk menganalisa bentuk dan jenis struktur yang dihasilkan setelah melalui proses heat treatment. Pengujian Struktur Mikro ini menggunakan Standar ASTM E-407. 
1) Hasil Struktur Mikro Tanpa Perlakuan Panas

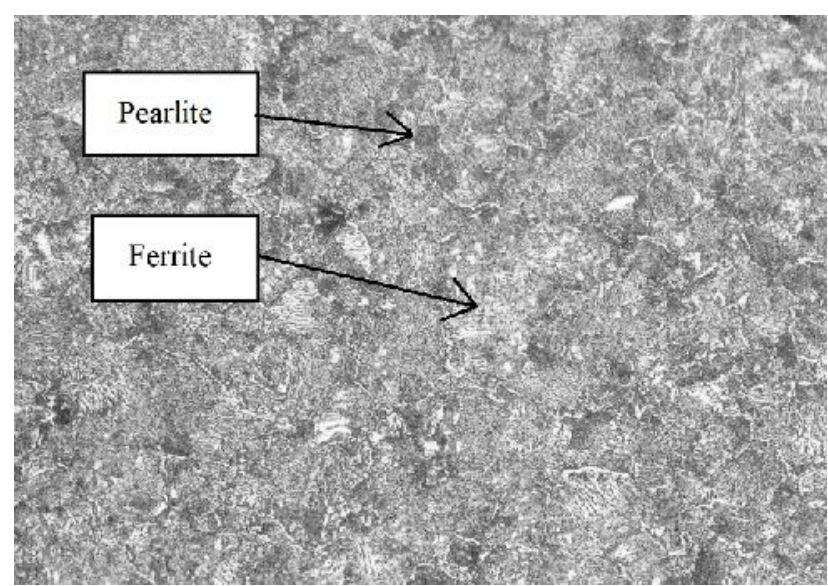

Gambar 8. Hasil struktur mikro raw material

Berdasarkan Gambar 9. Pada hasil uji struktur mikro spesimen tanpa perlakuan panas (raw material), terlihat struktur yang terbentuk yaitu pearlite dan ferrite, hal ini dikarenakan tidak dipengaruhi proses perlakuan panas.

Seperti Penelitian sebelumnya oleh Hadi Perdana (2017) Struktur mikro yang terbentuk pada bahan yang telah melalui proses perlakuan panas akan menghasilkan fasa Martensite dan fasa Bainit, sedangkan pada bahan yang tidak dilakukan proses perlakuan panas (raw material) bentuk fasanya terdiri dari Ferrite bagian yang terang dan fasa Pearlite pada bagian yang gelap[8].

2) Hasil Struktur Mikro dengan Proses Tempering temperatur $300^{\circ} \mathrm{C}$

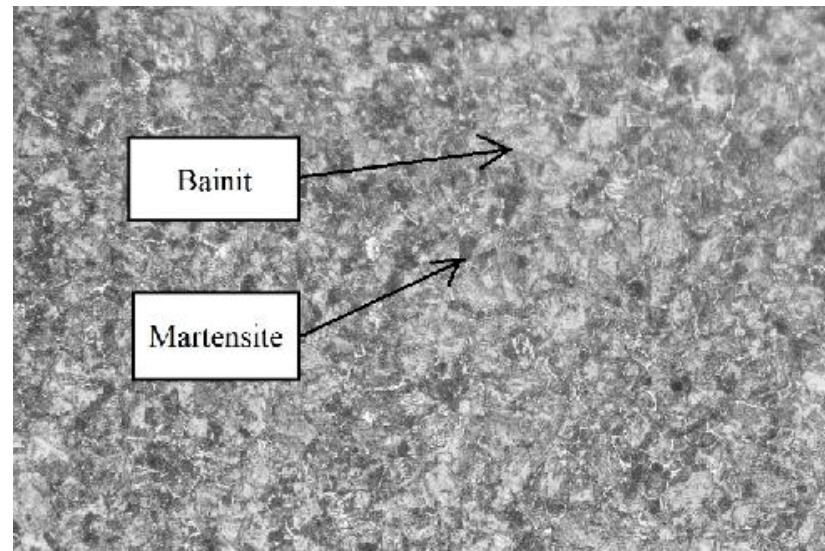

Gambar 9. Hasil Struktur Mikro dengan Proses

Tempering Suhu $300^{\circ} \mathrm{C}$ dengan pembesaran $100 \mathrm{x}$

Berdasarkan Gambar 10. Pada hasil struktur mikro spesimen yang telah melalui proses heating dengan temperatur austenite $850^{\circ} \mathrm{C}$ dengan holding time 60 menit, kemudian di quenching menggunakan media oli dan dilanjut dengan proses tempering dengan suhu $300^{\circ} \mathrm{C}$, terlihat perubahan struktur yang terbentuk yaitu bainit dan martensite terlihat cukup halus, hal ini dikarenakan telah melalui proses perlakuan panas. Pada spesimen ini mendapatkan nilai kekerasan yang cukup tinggi senilai 257,73 HV.

3) Hasil Struktur Mikro dengan Proses Tempering temperatur $400^{\circ} \mathrm{C}$

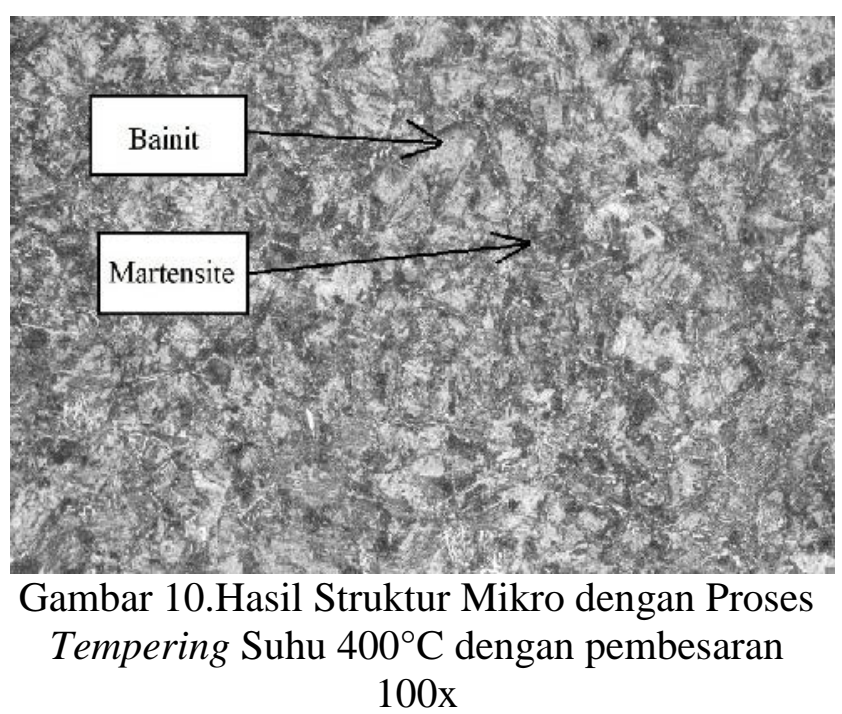

Berdasarkan Gambar 11. Pada hasil struktur mikro spesimen yang telah melalui proses heating dengan temperatur austenite $850^{\circ} \mathrm{C}$ dengan holding time 60 
menit, kemudian di quenching menggunakan media oli dan dilanjut dengan proses tempering dengan suhu $400^{\circ} \mathrm{C}$ dengan waktu penahanan 30 menit, terlihat struktur yang terbentuk fasa martensite cukup dominan dibandingkan spesimen sebelumnya, sehingga spesimen ini memiliki kekerasan lebih tinggi. Hal ini menunjukan pengaruh dari temperatur dan waktu tahan yang tepat akan menghasilkan kekerasan yang cukup tinggi[9].

4) Hasil Struktur Mikro dengan Proses Tempering temperatur $500^{\circ} \mathrm{C}$

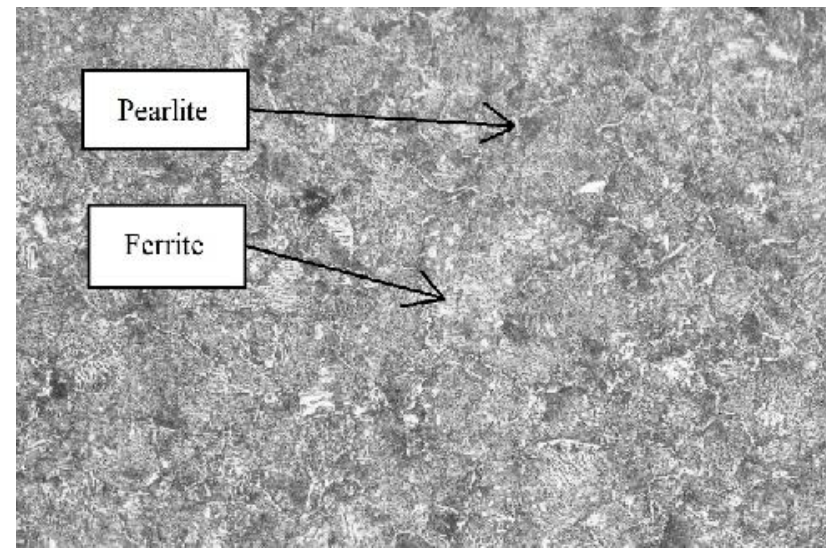

Gambar 11. Hasil Struktur Mikro dengan Proses

Tempering Suhu $500^{\circ} \mathrm{C}$ dengan pembesaran $200 \mathrm{x}$

Berdasarkan Gambar 12. Pada hasil struktur mikro spesimen yang telah melalui proses heating dengan temperatur austenite $850^{\circ} \mathrm{C}$ dengan holding time 60 menit, kemudian di quenching menggunakan media oli dan dilanjut dengan proses tempering dengan suhu $300^{\circ} \mathrm{C}$ dengan holding time 30 menit, terlihat struktur yang terbentuk yaitu Ferrite dan Pearlite yang masih dominan, perubahan struktur Martensite baru mulai tampak tetapi belum terdistribusi secara merata[10].

\section{KESIMPULAN}

Berdasarkan hasil penelitian dan analisis data pengujian sifat mekanik dan struktur mikro pada Baja AISI 1045 yang menggunakan variasi suhu tempering dapat di ketahui adanya peningkatan kekerasan baja AISI 1045 yang di tempering dengan temperatur berbeda-beda. Peningkatan kekerasan tertinggi terdapat pada spesimen uji yang diberi perlakuan panas tempering dengan temperatur $400^{\circ} \mathrm{C}$ selama 30 menit dengan nilai kekerasan
269,3 HV struktur mikro yang terbentuk yaitu fasa bainit dan martensite. Peningkatan kekerasan terendah terdapat pada spesimen uji yang diberi perlakuan panas tempering dengan temperatur $500^{\circ} \mathrm{C}$ dengan nilai kekerasan $250 \mathrm{HV}$ struktur mikro yang terbentuk yaitu fasa pearlite dan ferrite.

\section{DAFTAR PUSTAKA}

[1] Y. Handoyo, "Pengaruh Quenching Dan Tempering Pada Baja JIS GRADE S45C Terhadap Sifat Mekanis Dan Struktur Mikro Crankshaft," J. Ilm. Tek. Mesin, vol. 3, no. 2, pp. 102-115, 2015.

[2] S. Juliansyah, Dedikarnia, D. Yulianto, N. , Hamimah Abd. Rahmanb, and A.

Baharuddin, "Peningkatan ketangguhan impact pisau pemotong rumput dengan perlakuan panas menggunakan media pendingin radiator dan udara," J. Renew. Energy Mech., vol. 1, no. 01, pp. 17-26, 2019, doi: 10.25299/rem.2019.vol1(01).2179.

[3] P. Trihutomo, "Analisa Kekerasan pada Pisau Berbahan Baja Karbon Menengah hasil proses Hardening dengan meida pendinginyang berbeda," J. Tek. Mesin, pp. 28-34, 2015.

[4] A. Pramono, "Karakterisrik Mekanik Proses Hardening Baja Aisi 1045 Media Quenching Untuk Aplikasi Sprochet Rantai," J. Ilm. Tek. Mesin, vol. 5, no. 1, pp. 32-38, 2011.

[5] S. Yunaidi;Harnowo, "Pendingin Terhadap Sifat Mekanis Pada Proses Quenching Baja St 60," J. Tek. Mesin Politek. LPP Yogyakarta, pp. 57-63, 2015.

[6] E. Nugroho and S. D. Handono, "Pengaruh Temperatur dan Media Pendingin pada Proses Heat Treatment Baja AISI 1045 terhadap Kekerasan dan Laju Korosi," vol. 8, no. 1, pp. 99-110, 2019.

[7] R. S. M. B. P. H. Miharja Awan Jaya, "Pengaruh Suhu Tempering Terhadap Kekuatan Tarik, Kekerasan Dan Mikrostruktur Pada Sambungan Las Shielded Metal Arc Welding (SMAW) Baja Pegas Daun," Momentum, vol. 14, no. 1, pp. 16-22, 2018.

[8] dan M. E. Perdana Hadi, Anwar Moch. Syaiful, Juniarsih Andinnie, "Pengaruh Suhu 
dan Waktu Tempering Terhadap Kekerasan, Struktur Mikro, dan Laju Korosi Baja Tahan Karat Martensitik 13Cr3MO3Ni," pp. 37-44, 2017.

[9] F. Deniyasa, B. Santoso, and N. L. Indrayani, "Pengaruh Temperatur Dan Waktu Austemper Terhadap Sifat Mekanik Dan Struktur Mikro BAJA AISI 1045," J. Ilm. Tek. Mesin, vol. 6, no. 2, pp. 65-76, 2018.

[10] H. Wardoyo, "Analisis Pengaruh Perlakuan Panas Terhadap Kekerasan dan Struktur Mikro Material S45C dan SS400 Yang Digunakan Sebagai Alat Potong Kulit Sepatu," J. Tek. Mesin, vol. 04, no. 3, pp. 6772, 2015. 